\title{
An Analysis of the Accuracy of Prediction of Intraocular Implant Power in the Myopic Patient
}

\author{
P. McCORMACK*, A. EVANS, R. GREGSON \\ London
}

\begin{abstract}
Summary
A series of 90 eyes of $\mathbf{8 8}$ myopic patients who underwent extracapsular cataract surgery with intraocular lens implants (IOLs) between 1984 and 1989 were analysed in a retrospective study. The axial length as obtained by ultrasonic A scan and keratometry readings were applied to the SRK1 and modified SRK (SRK2) formulae ${ }^{1-3}$ and the result compared with the actual post-operative state achieved.
\end{abstract}

Myopic patients receiving lens implants of 17 dioptres (D) or less were identified by a search of the operating theatre records. The axial length was obtained using an Allergan Humphrey A scan biometer and the corneal curvature was assessed with Haag-Streit keratometer. The post-operative refractive error (assessed at least four months after surgery) was compared with the predicted outcome of the SRK1 and modified SRK formulae.

The IOLs used in these patients were: IOLAB 107G; Coburn 66 UV; Coburn 72 UV; Cilco SK21 and Rayner 870 UV.

For data analysis the post-operative refractive error was converted to the spherical equivalent (SE).

The SRK1 formula is $\mathrm{P}=\mathrm{A}-2.5$ $\mathrm{L}-0.9 \mathrm{~K}$, where $\mathrm{P}$ is the implant power, $\mathrm{A}$ is the A constant of the IOL, L is the axial length (in $\mathrm{mm}$ ) and $\mathrm{K}$ is the average corneal curvature (in dioptres).

The SRK2 formula is modified such that if:

$\mathrm{L}<20.0 \mathrm{~mm}$ then $\mathrm{A} 1=\mathrm{A}+3$

$\mathrm{L}<21.0 \mathrm{~mm}$ then $\mathrm{A} 1=\mathrm{A}+2$

$\mathrm{L}<22.0 \mathrm{~mm}$ then $\mathrm{A} 1=\mathrm{A}+1$

$\mathrm{L}<24.5 \mathrm{~mm}$ then $\mathrm{A} 1=\mathrm{A}$
$\mathrm{L}<24.5 \mathrm{~mm}$ then $\mathrm{A} 1=\mathrm{A}-0.5$

The mean axial length of eyes in this study was $26.9 \mathrm{~mm}$. The maximum was $30.16 \mathrm{~mm}$ and the minimum $24 \mathrm{~mm}$.

\section{Results}

Using the SRK1 formula the average absolute error was $2.16 \mathrm{D}$ with a range of $-7.2 \mathrm{D}$ to +8.5 D (Graphs 1 and 3). Using the SRK2 formula the average absolute error was $2.07 \mathrm{D}$ with a range of $-3.5 \mathrm{D}$ to $+7.8 \mathrm{D}$ (Graphs 2 and 3).

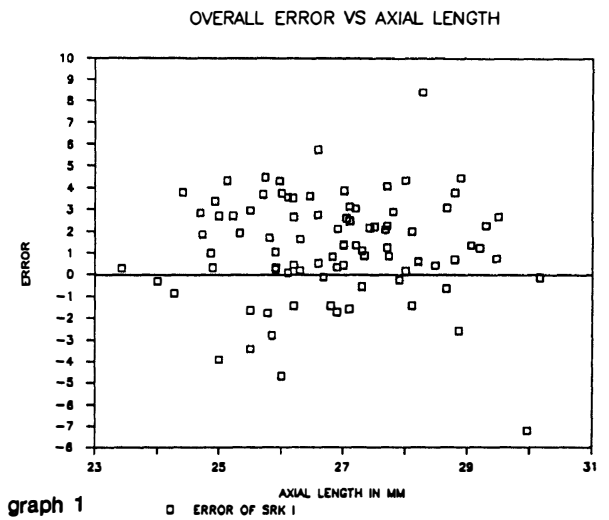


OVERALL ERROR VS AXIAL LENGTH

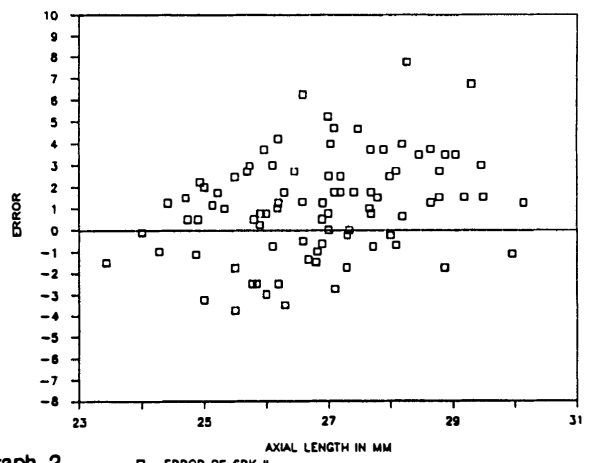

DISTRIBUTION OF ERRORS

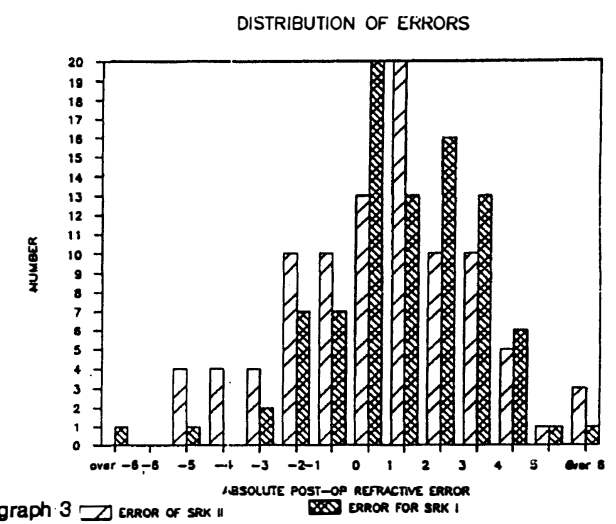

graph 3 CRROR of SRex "

graph 2

- ERROR OF SRK \|

Fig. A Comparison of Accuracy of Prediction of IOL Power.

\begin{tabular}{lcccccc}
\hline Data source & $\begin{array}{c}\text { Number } \\
\text { of eyes }\end{array}$ & < 1D & $\begin{array}{c}\text { Error (\%) } \\
\text { 1 to 2D }\end{array}$ & <2D & $\begin{array}{c}\text { Worst error } \\
\text { (D) }\end{array}$ & - \\
\hline $\begin{array}{l}\text { Sanders 1980 (emmetropes) } \\
\text { Hoffer 1981 }\end{array}$ & 923 & 81 & 15 & 4 & 6 & 5 \\
$\quad \begin{array}{l}\text { (hypermetropes) } \\
\text { Sanders 1981 (emmetropes) }\end{array}$ & 654 & 86 & 9 & 5 & 2.5 & 2.6 \\
\hline $\begin{array}{l}\text { Our study SRK1 (myopes) } \\
\text { Our study SRK2 (myopes) }\end{array}$ & 90 & 30 & 14 & 2 & 3.8 & 3.1 \\
\hline
\end{tabular}

fig. $b$

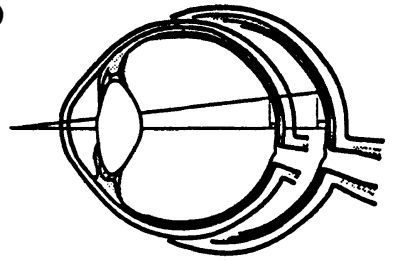

Off axis $A$ scan in a longer myopic eye may result in a greater error of axial length

fig. C

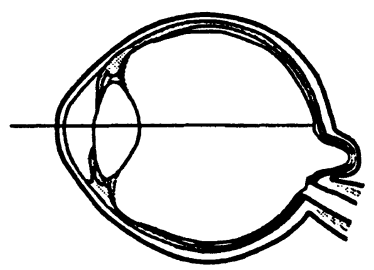

A scan missing a posterior pole staphyloma will result in a large post operative myopia

fig. $d$

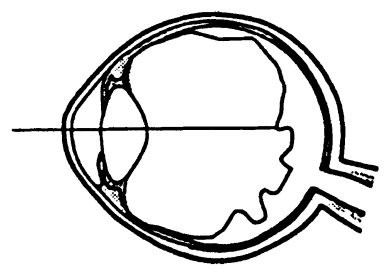

Reading from the posterior hyaloid face, especially easy if there is disbelief in the true extremely large axial length Again, post operative myopia will result 


\section{Conclusions}

The wide variability of errors obtained in this study when compared with other workers using the SRK formula for emmetropic ${ }^{2,5}$ and hypermetropic patients ${ }^{4}$ suggests that the accuracy of prediction of the IOL power is reduced in patients with axial myopia. (Fig. A) We suggest that the errors may arise from multiple sources:

(1) A relatively small error in alignment of the ultrasound beam in a long eye will induce a proportionately larger error in the measured axial length. (Fig B)

(2) If the ultrasound beam misses a posterior pole staphyloma the axial length will be falsely short. (Fig. C)

(3) If the true axial length exceeds the limits of the biometer $(32 \mathrm{~mm})$ the sonic reflection of PVD may be mistaken for the retinal echo. (Fig. D)

(4) The anterior chamber (AC) depth will be greater in the long eye and thus the A constant of the IOL may well be incorrect.
We are unable to find any statistical link between any of the variables (axial length, corneal curvature or A constant) and the refractive error obtained. It may be that there were inaccuracies in the pre-operative measurements or that other factors (such as AC depth) should be taken into account. Key words: Implant (IOL). Myopic. Prediction.

\section{References}

${ }^{1}$ Ratzlaff J, Sanders D, Kraff M: A Manual of Implant Power Calculations: SRK TM Formula. Medford, Oregon 1981.

${ }^{2}$ Sanders D and Kraff M: An improvement of intraocular lens power calculation using empirical data. Am Intra-ocular Implant Soc J 1980, 6: 263-

${ }^{3}$ Retzlaff J: Posterior chamber lens implant power calculations: Regression formulas. Am Intra-Ocular Implant Soc J 1980, 6: 268-

${ }^{4}$ Hoffer KJ: Intraocular lens calculation: the problem of the short eye. Ophthal Surg 1981, 12: 269-

${ }^{5}$ Sanders D et al Comparison of the accuracy of Binkhorst, Colenbrander and SRK implant power prediction formulas. Am Intra-Ocular Implant Soc J 1981, 7: 337-41. 